\title{
Primeros vagidos de tipografía y biblioiconografía mexicana del siglo XVI
}

\section{Early Signs of Sixteenth-Century \\ Mexican Typography and Biblio-iconography}

\author{
GuAdALupe RODRÍGUEZ DOMÍNGUEZ ${ }^{1}$ \\ http://orcid.org/0000-0002-9862-5417 \\ ${ }^{1}$ Facultad de Ciencias Sociales y Humanidades \\ Universidad Autonoma de San Luis Potosi \\ Av. Industrias, 101-A, San Luis Potosi, 78.399, Mexico \\ guadalupe.dominguez@uaslp.mx
}

Resumen El estudio de la tipografía y la iconografía de la imprenta en México del siglo XVI sigue siendo un tema sin agotar. Aunque se han realizado algunos acercamientos al tema desde diversas disciplinas faltan aún muchas aristas por atender. En este artículo se propone una nueva aplicación teórico-metodológica, la del análisis material, que permite rescatar información puntual sobre las características de cada una de las piezas usadas en el proceso de impresión, a partir de la mancha de tinta que estas dejan en el papel. Con el registro exhaustivo de los tipos y de los grabados xilográficos presentes en los impresos se forman los muestrarios de materiales que poseía cada imprenta. Estos muestrarios aportan información útil para la identificación del uso de los materiales impresorios durante el período activo de las imprentas. El análisis de los usos permite, a su vez, reconstruir parte de la intrahistoria de cada uno de los talleres de impresión.

Palavras Clave imprenta manual mexicana, tipografía, biblioiconografía

Recibido: 01 nov. 2018 | Revisto por la autora: 12 enero 2019 | Aprobado: 06 fev. 2019 http://dx.doi.org/10.1590/0104-87752019000200008

Varia Historia, Belo Horizonte, vol. 35, n. 68, p. 565-594, mai/ago 2019 
ABstract The study of the typography and iconography of printing in sixteenth century Mexico is a question that has yet to be exhausted. While different approaches have been proposed, there are still many elements to study. This paper proposes the application of the newest material analysis methodology to obtain detailed information about the items used for the printing press, based on the traces of ink left on the paper. A comprehensive record of the print types and woodcuts used can build material repertoires of each printing house. These repertories provide outstanding information about the printing materials used when they were in operation. In addition, the analysis of material uses also enables us to reconstruct the internal history of each printing house. KEYWORDs Mexican manual press, typography, biblio-iconography

\section{LA LlegadA DE la imprenta A MÉXico}

La introducción de la imprenta en territorio continental americano se da, como ha sido señalado en repetidas ocasiones por la crítica especializada, en el año 1539, gracias a las gestiones realizadas hacia 1535 por fray Juan de Zumárraga, primer obispo de México, ante el Emperador Carlos V (Grañén, 2010, p.197). Las necesidades de la instauración de esta tecnología se ceñían básicamente a cuestiones prácticas: estudio de los españoles recién asentados en el Virreinato de la Nueva España y apoyo a las labores de evangelización de los naturales. ${ }^{1}$ No obstante, la llegada de la innovación tecnológica, que representaba en ese momento la imprenta de tipos móviles, a la América Española tendría una gran trascendencia que superó con creces las primeras motivaciones de sus iniciadores.

1 Entre 1536 y 1538 se registra un Memorial del chantre Cristóbal de Pedraza, en el que comunica al monarca "que un maestro imprimidor tiene voluntad de servir a vuestra majestad con su arte y pasar a la Nueva España a empremir allá libros de iglesia, de letra grande y pequeña, $y$ de canto y otros libros pequeños para la instrucción de los indios,... el qual ansimismo sabe yluminar y hacer otras muchas cosas" (GRAÑÉN, 2010, p.197). 
La imprenta llega a Nueva España siendo una filial de la casa sevillana de los Cromberger, y fue regentada desde sus inicios, en 1539, por un italiano, cuyo nombre lexicalizado al español es conocido como Juan Pablos. Este primer taller mantiene el monopolio de los productos editoriales hasta 1558, año en el que Antonio de Espinosa obtiene el permiso del Rey, mediante Cédula Real, para instalar su propia imprenta, la segunda instaurada en la América Española (Grañén, 2010, p.222-223). Gracias al contenido de dicha Cédula, que establecía "que el arte del amprenta se husase y exerçiese libremente en esa tierra [Nueva España] como se usa en estos reynos [España]" (Grañén, 2010, p.222), a partir de ese momento y hasta los albores del siglo XVII, operarán varios talleres de impresión más en la ciudad de México. En lo que resta del siglo trabajan de manera activa las siguientes imprentas: Pedro Ocharte, Pedro Balli, Antonio Ricardo, Luis y Melchor Ocharte, y ya casi al final de la centuria, Enrico Martínez.

Así como sucedió con la introducción de la imprenta en España, la difusión de textos impresos con tipos móviles transformó la concepción del mundo gráfico en el Virreinato de la Nueva España, aunque con algunas diferencias. Mientras en España la cultura visual de la tipografía adquirió un lugar de importancia junto a las manifestaciones orales y a las auditivas (McLuhan, 1969), en Nueva España antes de que pudiera darse la aculturación tipográfica de los propios naturales, fue necesaria la adaptación del alfabeto latino para el registro, descripción y comprensión de las lenguas precolombinas, que, como sabemos eran ágrafas (Garone, 2014a), por lo que predominaba la transmisión del conocimiento y de las ideas por la vía oral, y también visual, pero a partir de ideogramas y no de la palabra o frase escrita, representada con un sistema alfabético.

Con la encomiable tarea filológica por parte de los frailes de las diferentes órdenes religiosas, ${ }^{2}$ recién asentados en el territorio americano,

2 Mendieta narra algunos episodios de convivencia entre frailes e indígenas, donde se aprecian las prácticas de recolección de datos para el conocimiento de las lenguas amerindias y las grandes dificultades a las que se enfrentaban en el proceso de comprensión de las mismas. MENDIETA, Gerónimo de. Historia eclesiástica indiana. México: Salvador Chávez Hayhoe, s.a., vol III. p.134. 
se elaboraron y llevaron a las prensas los primeros vocabularios y artes de gramática en náhuatl, tarasco, zapoteco, mixteco, huasteco, otomí, zotzil y de la lengua cuchona. ${ }^{3}$ Estos vocabularios y artes sirvieron a su vez para traducir a las lenguas de los naturales las doctrinas cristianas, las cartillas y otros textos de evangelización. Pero los productos editoriales mexicanos del siglo XVI no solo apoyaron las tareas de evangelización e hispanización, ${ }^{4}$ también fueron destinados al estudio de los integrantes de las órdenes religiosas, como, por ejemplo, las obras para la Compañía de Jesús (Tristes y Pónticas de Ovidio, Gramáticas latinas del lusitano Manuel Álvares, Emblemas de Alciato, Introducción a la Dialéctica de Aristóteles de Francisco Toledo, etc.), y para los alumnos de la recién fundada Universidad Pontificia, como serían los textos filosóficos de Alonso de la Veracruz o la obra didáctica de Cervantes de Salazar, conocida como Diálogos latinos, escrita con la finalidad de ofrecer un instrumento para que los alumnos practicaran latín, solo por dar unos cuantos ejemplos.

\section{ESTUDIOS SOBRE LOS PRIMITIVOS IMPRESOS MEXICANOS DESDE LA PERSPECTIVA TIPOGRÁFICA E ICONOGRÁFICA}

Un somero recorrido por los productos editoriales mexicanos del siglo XVI evidencia la solidez del programa intelectual y evangelizador de la Corona Española, dentro del cual cada uno de los diferentes actores tiene un lugar preponderante. Los franciscanos y dominicos,

3 Durante el siglo XVI, además de en español y en latín, se publicaron obras en todas estas lenguas, mediante la adaptación de los tipos móviles del alfabeto latino. En La imprenta en México en el siglo XVI, de los 222 registros de impresos de existencia comprobada (suma de ediciones propiamente dichas e impresos menores), he documentado 84 publicaciones exclusivamente en español, 82 en latín, 3 en náhuatl, 1 en tarasco y 1 en mixteco. Otras ediciones más fueron publicadas combinando diversos idiomas: 20 en español y náhuatl; 10 en español y latín; 7 en español, latín y náhuatl; 4 en español y tarasco; 2 en español, latín y tarasco; 2 en español y mixteco; 1 en español, latín y huasteco; 1 en español, náhuatl y otomí; 1 en español y zapoteco; 1 en español y zotzil; 1 en latín y náhuatl; 1 en latín y zapoteco y 1 en español y lengua chuchona. RODRÍGUEZ, 2018.

4 La empresa de evangelización de los naturales era el eje principal de las políticas de la Corona, y la enseñanza de la lengua castellana fue uno de los vehículos para lograrla, no obstante, también promovió la asimilación de la cultura hispana. RODRÍGUEZ, 1999, p.43. 
seguramente por haber sido los primeros en arribar a Nueva España, acapararon la producción de obras en náhuatl, tarasco, zapoteco, mixteco y en lengua chuchona; los agustinos, además de náhuatl y tarasco, se centraron en otras lenguas como la huasteca y la otomí; el clero secular se dedicó sobre todo a la publicación de textos en latín y español; los jesuitas se caracterizaron por haber publicado solo una obra en lengua náhuatl y el resto en latín y español. El resto de la producción editorial mexicana del XVI pertenece a autores de variada formación: médicos, catedráticos y estudiantes de la recién fundada Universidad Pontificia, oidores, jurisconsultos, entre otros.

En este sentido, no solo es relevante la labor de los autores o el contenido y la intencionalidad de las obras, sino también habría que rescatar la importancia de cada uno de los talleres de impresión, sus operarios y todos aquellos que hicieron posible que el conjunto de obras, brevemente descritas arriba, pudiera salir a la luz. Las siete imprentas con actividad comprobada en México en el siglo XVI (Juan Pablos, Antonio de Espinosa, Pedro Ocharte, Pedro Balli, Antonio Ricardo, hermanos Ocharte y Enrico Martínez) enfrentaron, sin duda, una gran cantidad de obstáculos, que debieron sortear para poder concretar sus propios proyectos editoriales. Las restricciones civiles, administrativas, de censura eclesiástica impuestas al impreso a raíz del Primer Concilio Provincial Mexicano en 1555 (Fernández, 2008, p.105-123), que intensificaban, inclusive, la aplicación de la legislación del libro peninsular, sumadas a problemáticas más técnicas y prácticas, como serían el suministro de los materiales impresorios (papel, tinta, prensas, fundiciones tipográficas, adornos tipográficos, grabados xilográficos, iniciales ornamentales, etc.), instan a revalorizar, mediante un estudio exhaustivo y con nuevas propuestas teórico-metodológicas, el rol que tuvo la imprenta mexicana en la construcción de la cultura escrita novohispana.

Centrándonos en la parcela de los materiales impresorios, el registro del stock perteneciente a cada una de las imprentas mexicanas activas durante el siglo XVI ha tenido una larga andadura. Extrayendo algunas muestras de tipos, ilustraciones, adornos tipográficos, orlas, iniciales grabadas de los propios impresos conservados, se ha desarrollado una 
discusión acerca del uso que cada uno de los talleres daba a sus propios materiales. Es decir, a partir de la mancha de tinta sobre el papel que dejaban dichos materiales en el papel impreso, se han identificado las preferencias de uso de los mismos por cada uno de los impresores. También se han señalado, de manera más parcial, los posibles traspasos de esos materiales entre cada una de las imprentas. No obstante, quedan aún muchos elementos por atender, como se demuestra con el siguiente recorrido de los estudios realizados sobre el tema.

De la primera imprenta mexicana, la de Juan Pablos, Valton estudió los tipos utilizados, centrándose específicamente en el tamaño y dejando de lado el análisis minucioso de su diseño, por ejemplo, registra: tipo canon $280 \mathrm{G}$ para grandes títulos; tipo misal $136 \mathrm{G}$ para pequeños títulos, encabezamientos y colofones; tipo texto $98 \mathrm{G}$ para texto ordinario; tipo texto $82 \mathrm{G}$ para texto. Con respecto a los tipos redondos documenta los tipos $240 \mathrm{R}, 99 \mathrm{R}$ y $81 \mathrm{R}$, describiendo algunas de sus características (Valton, 1939, p.239-278).

Millares y Calvo indican una nueva fundición no documentada por Valton: tipo $75 \mathrm{G}$ para apostillas y composición condensada. Asimismo, ahondan en los datos proporcionados por el bibliógrafo acerca de los tipos de Juan Pablos, aportando elementos sobre el diseño de cada uno de ellos: tipo $82 \mathrm{G}$ utilizado fundamentalmente para texto; tipo $280 \mathrm{G}$ "de unos 40 puntos modernos" con "mayúsculas particularmente adornadas y dibujo extravagante"; tipos 136G en dos formas distintas (con líneas paralelas en el interior de las mayúsculas o sin ellas, con puntos en lugar de líneas interiores): 136Ga utilizados de 1540 a 1550 y $136 \mathrm{~Gb}$ de 1550 a 1560; tipo 98G “equivalente a 14 puntos de hoy", cuya

forma de sus minúsculas es la misma en todos los libros de Pablos, no importa a qué época pertenezcan, si bien en los impresos desde 1550, inclusive, tienen una regularidad y una nitidez mayores. En cuanto a las mayúsculas de dicho tipo 98G, comprobamos que son las mismas en cuanto a su forma (no naturalmente en lo que concierne a su tamaño) a las del tipo $136 \mathrm{G}$ en su variedad b. Quiere esto decir, a juicio nuestro, 
que el prototipógrafo mexicano usó a partir de los primeros meses de 1550 un tipo nuevo 136G, cuyos punzones reprodujeron, agrandándolas, las mayúsculas del 98G, y no sólo agrandándolas, sino dándoles una mayor elegancia y perfección. [...] Dice Valton que estos tipos "con mayor probabilidad, salieron fundidos, en México, por Antonio de Espinosa, quien, seguramente, durante los años anteriores, había trabajado, como fundidor de letra y oficial tipógrafo, en el taller de Juan Pablos" (Millares; Calvo, 1990, p.24-34).

Millares y Calvo citan a Valton fuera de contexto, provocando con ello una inconsistencia cronológica, ya que los caracteres $136 \mathrm{~Gb}$ aparecen por primera vez en una edición de Pablos del 12 de febrero de 1550 y Antonio de Espinosa firmó el contrato para trabajar con Pablos en Sevilla el 24 de septiembre del mismo año.

En realidad lo que Valton quiso decir, fue que en su última edición conocida, Manuale sacramentorum, 1560, Pablos "nos presenta unos caracteres góticos más o menos del mismo estilo y tamaño que $280 \mathrm{G}$ y $136 \mathrm{G}$, pero de un corte más firme", concluyendo que estos tipos debieron ser fundidos por Espinosa cuando ya se encontraba en México (Valton, 1939, p.260-261). Ni las conclusiones de Valton, ni las observaciones de Millares y Calvo son correctas. Valton con la afirmación de un "corte más firme" de los tipos da a entender que se trata de nuevas fundiciones, cuando la verdad es que los tipos 280 G llegaron de Sevilla y no se volvieron a fundir en México, y los tipos $136 \mathrm{G}$ parece que sí se manufacturaron en México, pero no coinciden con el diseño anterior. Estas y otras incongruencias derivadas de suposiciones acerca del origen de los materiales tipográficos se dan, precisamente, por la falta de estudios sistemáticos exhaustivos de los insumos utilizados por cada imprenta, que deben cruzarse y complementarse necesariamente con las pocas fuentes documentales conservadas.

Aunque Millares y Calvo tampoco profundizan en el análisis de los tipos redondos y cursivos, uno de sus grandes aportes es la identificación de algunas letras cursivas utilizadas por Juan Pablos, que no parecen 
pertenecientes a una fundición de caracteres móviles, sino más bien "pareciera que han sido xilografiadas" (Millares; Calvo, 1990, p.34). ${ }^{5}$

Grañén ha analizado magistralmente los grabados de la imprenta de Juan Pablos; salvo en contadas excepciones, debido a la falta de acceso a las ediciones, documentó y analizó la mayoría de los materiales del taller: grabados, tipografías, ornamentos y letras ornamentales capitulares. Sin embargo, solamente profundiza en el análisis de los grabados y del resto de los materiales menciona algunas de sus particularidades. Además, en el apartado "Cronología de los grabados de Juan Pablos", señala de manera sucinta, mediante las iniciales "PO., refiriéndose a Pedro Ocharte y "PB., a Pedro Balli, si esos grabados fueron utilizados también por dichas imprentas. Asimismo, identifica los grabados provenientes de la imprenta sevillana de los Cromberger, que fueron documentados previamente por Griffin (Grañén, 2010, p.145-154).

Con respecto a otras imprentas, Stols, por su parte, dedica sus esfuerzos a la recopilación de los datos disponibles acerca del segundo impresor en México, Antonio de Espinosa, y del tercero, Pedro Ocharte. La reconstrucción que realiza es importantísima y ha aportado mucha luz sobre las actividades de cada taller. No obstante, en los terrenos bibliográfico, tipográfico e iconográfico se limita a presentar el listado de obras editadas por cada imprenta y a reproducir algunas de sus portadas y/o apartados textuales relevantes, sin penetrar en su estudio (Stols, 1989; 1990).

De la Maza en su monografía sobre el último impresor del siglo XVI, Enrico Martínez, recorre las diferentes facetas de su vida: impresor, astrólogo, geógrafo, médico, así como su papel en el diseño del desagüe

5 El uso de tipos xilografiados en la imprenta mexicana tanto redondos como cursivos se advierte, además de la imprenta de Juan Pablos, en la de Antonio de Espinosa. Seguramente los impresores querían dar realce y elegancia a la composición de portadas y encabezamientos interiores, donde aparecen estos tacos, sin efectuar una inversión tan grande como era la adquisición de una fundición de tipos móviles de cuerpo mayor. Así, con el tallado en madera de una o dos líneas para ser utilizadas en una sola obra, suplían la escasez de tipos de cuerpo mayor, y a la vez evitaban gastos excesivos. Una muestra de esta práctica se aprecia precisamente en una de las primeras obras que publica Antonio de Espinosa en México: Grammatica Maturini Tractatvs, 1559. RODRÍGUEZ, 2018. 
de la Ciudad de México. Es comprensible que la sección dedicada a los impresos del siglo XVI abarque escasas diez páginas, debido a que el inicio de actividades de las prensas de Martínez tiene lugar en 1599. Por otro lado, el investigador se centra, sobre todo, en un registro bibliográfico de los impresos y no en su análisis propiamente dicho (Maza, 1991, p.36-42 y p.XV-XVII).

Yhmoff ofrece un panorama más abarcador y original en sus diversas publicaciones sobre los materiales utilizados por distintas imprentas mexicanas del XVI, con el registro de las letras capitulares, los grabados y algunos adornos tipográficos. Registra materiales de prácticamente todas las imprentas activas: Juan Pablos, Antonio de Espinosa, Pedro Ocharte, Pedro Balli, Antonio Ricardo y los herederos de Pedro Ocharte, faltando solo la de Enrico Martínez. Y no solo extrae cada una de las muestras, sino que ubica materiales de corte similar en otras imprentas europeas, con lo que trasciende el ámbito mexicano, estableciendo posibles relaciones comerciales entre las imprentas establecidas en México y el mercado del insumo de los materiales impresorios en otras latitudes (Yhmoff, 1991; 1990; 1987; 1981-1982; 1974; 1973). Desafortunadamente, aunque Ymhoff aporta grandes avances a las investigaciones sobre el tema, el hecho de que su investigación se acote a la colección de la Biblioteca Nacional de México, deja el análisis en un estado muy parcial.

En una línea similar a la desarrollada por Yhmoff, Cid Carmona se dedica a documentar las letras capitulares adornadas y los grabados presentes en los impresos de corte médico a cargo del impresor Antonio Ricardo. No obstante, y precisamente por ceñirse solamente a las obras de medicina, no da cuenta de toda la gama del uso de los materiales y sus combinaciones practicada por el impresor (Cid, 2005, p.40-45).

De las investigaciones citadas anteriormente, la de Grañén es la única realizada sobre la base de una sólida metodología desde la perspectiva de la historia del arte. El resto de los trabajos se limita a registrar de manera incompleta la aparición de los materiales en los diferentes impresos, documentando su tamaño, algunas características de sus diseños y, en casos excepcionales, como el de Yhmoff, rastreando su posible origen en el mercado europeo. 


\section{ANÁLISIS TIPOGRÁFICO Y BIBLIOICONOGRÁFICO}

El estado actual de los estudios hace patente, pues, la necesidad de abordar de manera más sistemática el análisis de los materiales impresorios de los talleres mexicanos del siglo XVI. ${ }^{6}$ En esta línea, como parte de la elaboración de la nueva Tipobibliografía Mexicana, la Imprenta en México en el siglo XVI (Rodríguez, 2018) se ha realizado el proceso de recolección de muestras de todos los materiales que aparecen en las ediciones conservadas, ${ }^{7}$ a fin de crear repertorios de cada impresor de fundiciones tipográficas, grabados xilográficos, adornos tipográficos e iniciales grabadas. ${ }^{8}$ Cada repertorio se forma extrayendo las imágenes

6 En este sentido, es importante señalar que existen otros trabajos abarcadores que también recogen los materiales utilizados por varias imprentas novohispanas, como "letrerías", "capitulares", "ornamentos tipográficos" e "imágenes", pero se enfocan en colecciones específicas y no en la producción total de cada una de las imprentas que estudian. Me refiero a Historia de la imprenta y la tipografía colonial en Puebla de los Ángeles (1642-1821) (GARONE, 2014b) y a Los impresos mexicanos del siglo XVI en la Biblioteca Nacional de México (YMHOFF, 1990), que, por centrarse en el estudio de los ejemplares de una sola colección y no de toda la producción de cada una de las imprentas abordadas, presentan resultados muy parciales de un todo editorial. Dichos resultados, no por ello menos encomiables, no permiten, por ejemplo, asignar responsables de impresión de las ediciones sine notis, trazar las líneas de continuidad del uso de los materiales y su desgaste, identificar hábitos de composición por etapas de los diferentes talleres de impresión, reconstruir los traspasos de materiales entre las imprentas, etc. Por ello mismo, estos trabajos no siguen el rigor metodológico y de análisis tipobiblioiconográfico, ni la exhaustividad con la que se realiza la recolección de materiales impresorios para la elaboración de las Tipobibliografías, en las que se procura recoger todos los materiales presentes en todas las ediciones conservadas de cada una de las imprentas estudiadas, independientemente de su ubicación en cualquier biblioteca o acervo del mundo.

7 De las 222 ediciones que conforman la Tipobibliografía La imprenta en México en el siglo XVI, he revisado directamente 211 ediciones, han quedado pendientes de análisis solo 11 de ellas, debido a que ha sido imposible localizarlas; de estas 11, 9 son impresos menores (cartas poder, de limpieza de sangre, de mercancías de naos, etc.) que, por la misma tipología del impreso, seguramente no contienen ilustraciones. De las 211 ediciones localizadas he realizado el análisis material minucioso de 463 ejemplares, de los cuales he extraído los materiales impresorios que forman cada uno de los repertorios (tipografías, grabados xilográficos, adornos tipográficos e iniciales grabadas). RODRÍGUEZ, 2018. Estos materiales debidamente organizados y analizados se publicarán próximamente en el Repositorio Biblioiconográfico Mexicano del siglo XVI (UASLP), al que me referiré más adelante.

8 Fernández Valladares ha señalado con gran acierto que resulta "difícilmente disociable la labor de descripción [tipobiliográfica] de la de análisis tipográfico — si se quiere aspirar, entre otras 
de la mancha de tinta en el papel; con cada uno de estos registros ha sido posible reconstruir de manera parcial el stock de materiales de sendas imprentas. De manera parcial, claro está, ya que se trabaja con la evidencia material, con la impronta de uso de cada pieza utilizada para formar las ediciones, y no con fuentes documentales como podrían ser los inventarios de cada imprenta, los testamentos (en los que muchas veces se describe con detalle el patrimonio de los difuntos impresores a heredar), los contratos notariales o administrativos (en los que podrían inscribirse las transacciones comerciales entre las imprentas), y otra tipología de documentos que pudieran dar cuenta del conjunto de bienes perteneciente a cada imprenta. Desafortunadamente, dicha clase de documentación no se ha conservado o no se ha localizado en la actualidad; encontrar información al respecto en esta época sería casi un milagro, ya que, como señala García:

Tal escasez documental resulta comprensible por los diferentes eventos que afectarían la permanencia de la documentación virreinal. Podemos citar los motines sociales entre 1624 y 1692, la gran inundación de la capital entre 1629 y 1634, así como el robo de documentación para fines tan profanos como hacer cohetes en 1702, o para ser usados en la venta de bizcochos y pasteles en 1800 (García, 2017, p.168).

La suma de los eventos anteriores ha generado una gran pérdida de fuentes archivísticas. Por tanto, en vista de la falta de documentación para aclarar el panorama de los bienes de cada imprenta mexicana del XVI, ha sido necesario acudir a otras aplicaciones teórico-metodológicas, como el análisis tipográfico y biblioiconográfico.

Por cuestiones de espacio, en este trabajo me centraré solamente en el corpus de materiales perteneciente a las cuatro primeras imprentas

cosas, a la exhaustividad"; asimismo, ha puntualizado que si se quiere estudiar a profundidad la producción editorial de un taller de impresión "es necesario abordar ineludiblemente el trabajo tipobibliográfico en su doble dimensión de la descripción y la identificación de materiales tipográficos y ornamentales de todas las ediciones con datos ciertos" (FERNÁNDEZ, 2006, p.438-439). 
mexicanas: Juan Pablos, Antonio de Espinosa, Pedro Ocharte y Pedro Balli. Para el análisis tipográfico se ha seguido el método conocido como Proctor-Haebler, que permite distinguir las características distintivas de las tipografías, extrayendo la medición en milímetros de 20 líneas de texto compuesto con la misma fundición y el diseño de la "M" mayúscula para la tipografía gótica, y el diseño y amplitud de la cola de la "Q" para la redonda. Asimismo, para la tipografía redonda se han integrado otros elementos definitorios, como la posición del transversal de la "e" minúscula y el trazo de los remates de las mayúsculas. Asimismo, para la tipografía cursiva se ha integrado, además del diseño de la "M" y el de la cola de la Q", la amplitud de la barra de la "R".

A la metodología se sumaron otros principios metodológicos. ${ }^{9} \mathrm{El}$ de la combinación de caracteres formulado por Norton (Norton, 1970, p.96-103); el de la simultaneidad del uso de letrerías en impresos de una sola imprenta propuesto por Vervliet (Vervliet, 1968). Por otro lado, para los casos más complejos se ha aplicado el análisis de justificación de matrices diseñado por Moll, quien enseña que no se deben analizar nunca las letras aisladas, sino que "es preciso tener en cuenta su colocación en un conjunto formado por varias letras contiguas", tomando en consideración también el grosor de cada una de ellas, "el espaciado entre las líneas" y "en relación al rectángulo resultante cada letra debe estar su prevista verticalidad” (Moll, 1994, p.109-118).

En lo que respecta al análisis biblioiconográfico de los grabados xilográficos, adornos tipográficos e iniciales grabadas se ha registrado la fecha de primera aparición del material; medida de la pieza; su ubicación dentro de la obra y si existen imitaciones o relaboraciones en posteriores impresos. Asimismo, se establecen referencias cruzadas para los casos en que los mismos grabados aparezcan en ediciones de otras imprentas

9 La aplicación simultánea de todos los principios metodológicos, en caso de ser necesaria, ha sido establecida por Fernández Valladares en el Seminario Permanente de Bibliografía Material y Análisis Tipográfico, bajo su dirección, adscrito al Instituto Universitario Menéndez Pidal de la Universidad Complutense de Madrid. La descripción detallada de su propuesta se puede ver en "Indicios y evidencias para la asignación tipobibliográfica de pliegos sueltos burgaleses del siglo XVI”, FERNÁNDEZ, 2006, p.437-475. 
o para los casos en que una imprenta imite, mediante relaboraciones, los grabados pertenecientes a otra $\mathrm{u}$ otras imprentas. ${ }^{10}$

La inclusión del análisis biblioiconográfico junto con el tipográfico se justifica por la cantidad de ilustraciones presentes en las ediciones durante este período; de los 222 registros de impresos mexicanos recogidos durante la elaboración de la Tipobibliografía del siglo XVI, se han extraído los siguientes datos: ${ }^{11}$

- 64 impresos tienen solo una ilustración que aparece en la portada; - 63 tienen ilustraciones simultáneamente en portada y en el interior del texto;

10 Fernández Valladares ha sentado también las bases para la elaboración de repertorios biblioiconográficos en dos trabajos fundamentales sobre la materia y para el ámbito hispánico, señalando la importancia del registro de toda la información posible sobre cada grabado o elemento ornamental. La investigadora, entre otras cosas, propone "aplicar la mirada y los métodos tipobibliográficos a la biblioiconografía y al estudio de la ilustración de los impresos del siglo XV y XVI", con el objetivo de disponer de "repertorios visuales y atlas que hagan accesible tanto los materiales tipográficos como, en particular, los iconográficos de las distintas imprentas, convenientemente individualizados, codificados, reproducidos, descritos y clasificados, a partir de la metodología analítica subyacente a la elaboración de los modernos repertorios tipobibliográficos" (FERNÁNDEZ, 2012a, p.87-131; 2012b).

11 Como he mencionado anteriormente, el resultado de la investigación Tipobibliografía Mexicana del siglo XVI se ha publicado en formato de libro impreso con el título: La imprenta en México en el siglo XVI, RODRÍGUEZ, 2018. No obstante, por tratarse de una Tipobibliografía, en dicho trabajo solo se presentan muestras de los materiales tipográficos y no ha sido posible incluir las más de 640 piezas recogidas que conforman el repertorio de grabados xilográficos, a los que se suman una gran cantidad de elementos ornamentales e iniciales grabadas que aún no hemos terminado de contabilizar. Los resultados completos de la investigación biblioiconográfica se encuentran inéditos actualmente, pero se están preparando para ofrecerse en línea, de manera paulatina y hasta completarse, a partir del segundo semestre de 2019 en el Repositorio Biblioiconográfico Mexicano del siglo XVI, que formará parte de la Colección Patrimonio Documental del Repositorio Institucional Nínive, de la Universidad Autónoma de San Luis Potosí (México), cuya dirección corre a cargo de la Mtra. Rosalina Vázquez Tapia. A partir del registro sistemático de los materiales presentes en cada edición que conforma $\mathrm{La}$ imprenta en México en el siglo XVI, he organizado 4 repertorios de materiales impresorios: grabados xilográficos, tipografías, iniciales grabadas y elementos ornamentales (en este último se incluyen orlas, frontispicios, viñetas, adornitos, bandas filacterias para la composición de titulillos, marmosetes, etc.). 
- 16 solo presentan ilustraciones en su interior, gran parte de estas ediciones se ha revisado a partir de ejemplares únicos que están mútilos de portada, por lo que es imposible afirmar si allí contenían o no alguna imagen;

- 68 no incluyen ninguna ilustración, sin duda debido a la tipología documental de muchos de ellos: 22 son formularios administrativos (cartas poder, cartas de limpieza de sangre) y 24 pertenecen a lo que actualmente se conoce como literatura gris (bulas, mandamientos, anuncios de lectura de tesis de la Universidad Pontificia, breves, provisiones reales y calendario);

- 11 no fueron localizados, por lo que no se sabe si contenían imágenes.

En suma, 143 registros de ediciones o impresos menores, de los 222 documentados, incluyen al menos un grabado xilográfico. ${ }^{12}$ En términos porcentuales, se puede decir que más del $64 \%$ de la producción editorial mexicana del siglo XVI utilizó la imagen para completar o enriquecer el texto compuesto con las distintas tipografías: gótica, redonda y cursiva.

\section{ENTRAMADO DE MATERIALES}

\section{DE LAS PRIMERAS IMPRENTAS MEXICANAS}

La última edición conocida a cargo de la imprenta de Juan Pablos, antes de su fallecimiento, es el libro de música Manuale Sacramentorum, de agosto de 1560. Después de ese año, la producción de la primera imprenta mexicana se paraliza y no se conocen otras ediciones hasta 1563, cuando Pedro Ocharte "celebra la escritura de arrendamiento de la imprenta en $1^{\circ}$ de febrero de 1563", con su suegra, Jerónima Gutiérrez, viuda de Juan Pablos. El contrato tenía una duración de dieciocho meses, del $1^{\circ}$ de febrero de 1563 al 1º de septiembre de 1564 y mencionaba algunos de

12 Toda la información acerca del uso de los grabados y sus respectivas estadísticas se ha extraído de los datos recogidos durante mi investigación: Tipobibliografía Mexicana del siglo XVI. Los resultados completos se encuentran inéditos actualmente, pero ofrezco aquí algunos avances correspondientes a las primeras 4 imprentas mexicanas. 
los materiales arrendados: "dos imprentas", "tipos, ramas, viñetas" (Stols, 1990, p.5-7). Es lógico, por ello, que en septiembre de 1563 se emitan las licencias de impresión del Psalterium chorale secundum, a favor de Pedro Ocharte y Jerónima Gutiérrez, su suegra, en las que se les da reconocimiento de manera conjunta del oficio de impresores de libros. Después de 1564 se desconoce el tipo de transacción con la que Pedro Ocharte siguió trabajando, pero es evidente que conservó la imprenta, ya que operó de manera ininterrumpida al menos hasta 1572 , cuando es procesado por la Santa Inquisición. Stols afirma, sin fundamento alguno, que, además de los 3 "cuerpos de tipo gótico, heredados de Juan Pablos", Ocharte "usó otros diez cuerpos de tipo gótico, y quince de romano y cursivo, fundidos por Antonio de Espinosa y Juan Ortiz" (Stols, 1990, p.7).

Nada más lejos de la realidad... En términos generales, la imprenta del siglo XVI en América adolecía de esa abundancia de materiales tipográficos; considerar que una de ellas pudo haber poseído 28 fundiciones tipográficas hablaría de una producción masiva de impresos, con su correspondiente mercado de demanda, cuestión que definitivamente no existió. Bien es verdad que el taller de Ocharte siguió derroteros interesantísimos en lo que respecta a la adquisición y traspaso de materiales impresorios, pero no al punto de las afirmaciones hiperbólicas de Stols. En realidad, entre 1563 y 1571, Ocharte mantuvo en uso los materiales impresorios que habían sido de su suegro, Juan Pablos. Pero para poder reconstruir ese traspaso, habrá que empezar por el principio, por el stock de Juan Pablos.

Como mencioné antes, haciendo un recuento de los materiales utilizados por Pablos, tomando como base exclusivamente la huella que ha permanecido en los propios impresos, es posible reconstruir de manera parcial con qué insumos se conformaba el stock del taller. Gracias al análisis material se han identificado dos períodos bien delimitados entre 1540 y 1560, tiempo de trabajo continuo del taller. Durante el primero Pablos hizo uso de la remesa con la que llegó para instalar la imprenta en 1539, que coincide con muchos de los materiales utilizados por el taller de los Cromberger en Sevilla. En el terreno tipográfico es transparente el traspaso de los materiales sevillanos a México. En la parcela 
de la ilustración, a los que llegan de la península se suman otros, cuyo origen no ha sido posible rastrear, y de los que la crítica ha especulado que pudieron ser de manufactura novohispana, y, en especial, indígena. Un ejemplo de la parcialidad en la reconstrucción del corpus de cada imprenta y a la vez de los alcances de la metodología aplicada lo tenemos con los siguientes grabados xilográficos.

El grabado de San Jerónimo (68x99 mm) [v. Imagen 1] aparece en Doctrina christiana en lengva mexicana muy necessaria, de fray Alonso de Molina, impresa por Pedro Ocharte, en 1578, f. 80 v y en Psalmodia christiana, de fray Bernardino de Sahagún, impresa por Pedro Ocharte, en 1583, f. 181 v. Queda registrado, pues, en los muestrarios de ilustraciones de Ocharte. Sin embargo, rastreando la trayectoria del grabado sabemos que el mismo fue propiedad de Juan Varela de Salamanca y se localizó en la portada de la edición sevillana de Epístolas del glorioso dotor San Hieronymo, impresas por Juan Varela de Salamanca, en 1532 [v. Imagen 2]. De lo que se puede colegir que este grabado llegó en la primera remesa para instalar la imprenta, junto con Juan Pablos, en 1539.

A propósito de la imprenta de Juan Varela, Delgado menciona que algunos investigadores como Norton y Griffin han concluido que el material en poder de Pegnitzer pasó a Varela y de este a Cromberger. Juan Varela fue contemporáneo de Jacobo Cromberger, y la hija del primero (Inés) se casó con el hijo del segundo (Jácome). De esta manera se unieron los dos talleres de impresión más importantes de Sevilla (Delgado, 1996, p.691-693). Ante esta tesitura, el argumento de que el grabado debió pertenecer a los inventarios de Pablos y de ahí pasar a Ocharte es contundente, en virtud de que es innegable que se trata de la misma pieza, por la marca del impresor Pegnitzer ubicada al lado de una de las rodillas del santo y por el deterioro, en forma de muesca, en la parte central izquierda del marco. Se desconocen las razones por las que Pablos no lo utilizó en sus impresos, o bien pudo haberlo usado y no se ha conservado ningún testimonio de ello. Por tales circunstancias, en sentido estricto no se debe ubicar en los muestrarios de Pablos, ya que solamente debemos asentar la presencia de los materiales en las ediciones de cada impresor, pero sí es posible rescatar su origen y completar su tortuosa línea de traspasos. 


\section{Imagen 1: Grabado xilográfico de San Jerónimo en ediciones mexicanas.}

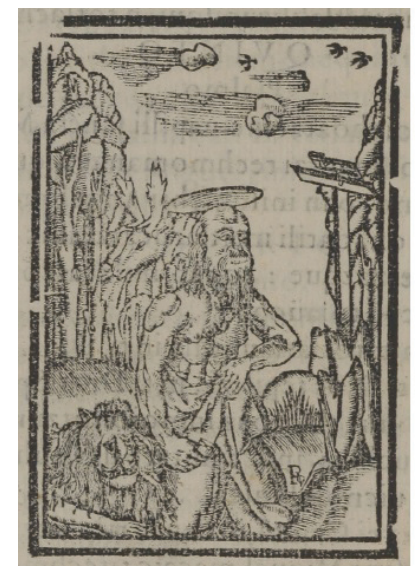

Psalmodia christiana, Pedro Ocharte, 1583, f. 181 v. Nettie Lee Benson Latin American Collection, University of Texas Libraries, The University of Texas at Austin. Primeros libros de las Américas (enero 2019). Recuperado de http://primeroslibros.org/detail.html?lang=es\&work_id=303966

Imagen 2: Grabado xilográfico de San Jerónimo en edición sevillana.

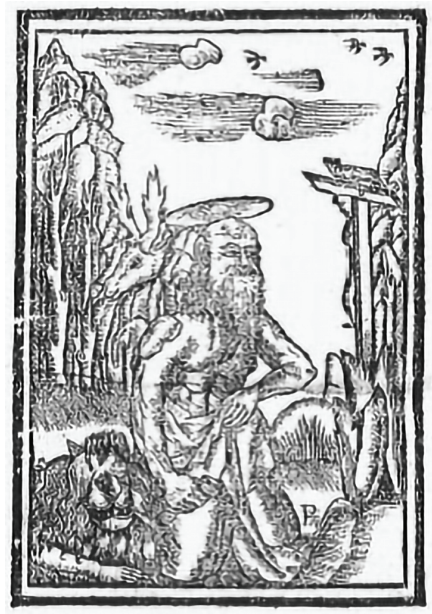

Epístolas del glorioso dotor San Hieronymo, Juan Varela de Salamanca, 1532, portada. Biblioteca Nacional de España. Ejemplar disponible en Biblioteca Digital Hispánica: http://bdh-rd.bne.es/viewer.vm?id=0000009698\&page=1 
Dejando de lado los orígenes, durante la primera fase identificada, de 1540 a 1550, Pablos trabajó solamente con cuatro fundiciones de tipos góticos: c. 275G, 132a G, 99a G, c. 72a G y con alrededor de 40 grabados xilográficos. Resulta curioso advertir que la imprenta se instala con muy pocos materiales, lo que lleva a pensar que en sus inicios los Cromberger no tenían demasiado interés en la producción editorial a realizarse en México. No obstante, para la década de los 50 y específicamente a partir de 1553, cuando la imprenta ya pasa a ser propiedad de Pablos, se advierte una significativa renovación. ${ }^{13}$ Es cuando se dejan de usar algunas de las primeras tipografías góticas traídas de Sevilla, suplantándolas con fundiciones de nuevo diseño; a lo que se suman nuevas adquisiciones de grabados xilográficos. Con respecto a las tipografías, en esta década se dejan de usar los tres primitivos diseños góticos 132a G, 99a G y c. 72a G, que son sustituidos por 132 b G, 99b G, 100 G, 72b $\mathrm{G}$ respectivamente, y se incorporan dos nueva fundiciones c. $160 \mathrm{G}$ y $81 \mathrm{G}$; asimismo, se suman los tipos redondos $100 \mathrm{R}, 81 \mathrm{R}$ y los cursivos 99 C y 80 C. En total, durante sus 20 años de trabajo, Pablos poseyó 14 fundiciones de tipografías: 10 de tipos góticos, 2 de redondos y 2 de cursivos (Rodríguez, 2018). Asimismo, a los 40 grabados iniciales, se van sumando paulatinamente otros, finalizando el año de 1560 con el registro de 127 grabados xilográficos, los cuales fueron utilizados en diversos impresos durante las dos décadas.

De estos materiales, los que pasan a la imprenta de Pedro Ocharte se han identificado también a través de las huellas dejadas por su imposición en los impresos, a falta de fuentes documentales que desglosen cada uno de los ítems. En cuanto a las fundiciones tipográficas, encontramos que pasan de Pablos solamente las 9 que utilizó de manera constante durante sus últimos años de operación: c. 275 G [v. Imagen 3], c. 160 G, 132b G, 100 G, 72b G, 100 R, 81 R, 99 C y 80 C; a estas se suma una nueva tipografía: c. 70 R. Estas 10 fundiciones aparecerán en los

13 Cronológicamente, la renovación del taller coincide con la firma por parte de Pablos de una escritura de préstamo de 500 ducados destinados a ciertos gastos relacionados con su imprenta. GRAÑÉN, 2010, p.209-210. 
impresos de Ocharte entre 1563 y 1571 (Rodríguez, 2018). En la tabla de abajo se puede observar las fundiciones utilizadas por cada imprenta y el comportamiento de sus traspasos.

Imagen 3: Muestra de tipografía 275 G, utilizada por Juan Pablos, Pedro Ocharte y Antonio de Espinosa.

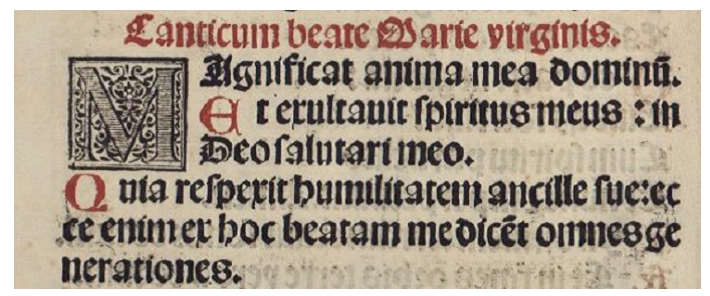

Psalterivm Antiphonarium Sanctorale, Pedro Ocharte, 1584, fragmento de f. 94 v.

Nettie Lee Benson Latin American Collection, University of Texas Libraries, The University of Texas at Austin. Primeros libros de las Américas (enero 2019). Recuperado de http://primeroslibros.org/detail.html?lang=es\&work_id=303968

Después de 1572 el taller de Ocharte sufre una serie de vicisitudes, derivadas de la denuncia hecha contra el impresor por "haber acabado libros en que había opiniones luteranas contra la veneración e intercesión de los santos, afirmando que aun sólo Dios se ha de rezar y no a ellos" (Fernández, 1914, p.86) y su posterior encarcelamiento por la Inquisición, por lo que su producción editorial se paraliza. Es hasta 1578 cuando vuelve a aparecer Ocharte en la escena tipográfica mexicana, con dos ediciones, una de ellas en colaboración con Antonio Ricardo, el quinto impresor en México: Vocabulario en lengua zapoteca, de autoría de Juan de Córdova. De 1578 a 1592 el taller mantiene su actividad de manera ininterrumpida, utilizando las tipografías de antes, con excepción de c. $160 \mathrm{G}$ y $100 \mathrm{R}$, que dejan de figurar en sus impresos. Los tipos $100 \mathrm{R}$ simplemente desaparecen y se desconoce su paradero, no obstante, los c. $160 \mathrm{G}$ pasan a manos de Pedro Balli, como veremos más adelante.

Lo más interesante de la imprenta de Ocharte, no obstante, se advierte en el movimiento de los materiales iconográficos. Su repertorio de grabados xilográficos contiene nada menos que 320 entalladuras, de 
las cuales, se han logrado identificar 56 como parte de la imprenta de Juan Pablos. También encontramos situaciones similares a las explicadas arriba sobre el grabado de Juan Varela de Salamanca, con otros grabados que no aparecen en los impresos de Pablos, pero sí en los de Ocharte, cuyo origen se ha podido rastrear hasta Sevilla. Un ejemplo tan intrincado como el anterior lo tenemos con el siguiente caso: aunque la imagen no fue documentada por Griffin en la imprenta de los Cromberger, se ha rastreado en Sevilla en la imprenta de Stalisnao Polo, en la obra de Ricoldo Montre, Improbatio Alconari, año 1500. Pues bien, este mismo grabado reaparece 67 años después en México en una edición de Pedro Ocharte: la imagen $4(129 \times 120 \mathrm{~mm})$ se extrajo del ejemplar digitalizado de Doctrina christiana en lengua castellana y çapoteca, de Pedro Ocharte, 1567, f. 19 r., de John Carter Brown Library. Con lo que es factible reconstruir su línea de traspasos: el grabado perteneció inicialmente a Stalinao Polo, posteriormente pasó a la imprenta de los Cromberger, por ello mismo llegó a América con Juan Pablos, y así pasó a Ocharte. A pesar de que no se ha identificado en impresos de los Cromberger, ni en los de Pablos, su trayectoria queda completada con estas evidencias.

Imagen 4: Grabado xilográfico de la Conversión de infieles.

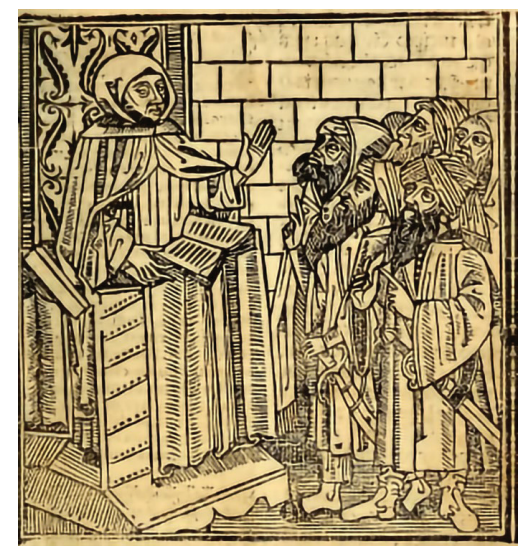

Doctrina christiana en lengua castellana y çapoteca, Pedro Ocharte, 1567, f. 19 r. John Carter Brown Library-Mexico Incunables Collection.

"Courtesy of the John Carter Brown Library at Brown University". 
En lo que respecta a Pedro Balli, es obvio que se beneficia, sin proponérselo (seguramente), del cese de actividades de la imprenta de Ocharte durante la década de los 70 debido al proceso inquisitorial. Para 1574 sorprende ubicar la presencia de muchos de los materiales del último en las ediciones del primero, por ejemplo, los tipos c. 160 G, 100 G, 99 C [v. Imagen 5] y 80 C (Rodríguez, 2018). Los tipos redondos que no se habían visto en otras imprentas y, en consecuencia, sugieren haber sido de propiedad de Balli son c. 240 R, 118 R, 98 R y 84 R. De los cuales, 118 $\mathrm{R}$ y $84 \mathrm{R}$ son utilizados en las ediciones del impresor durante veintiséis años: 1574-1600; 240 R y 98 R solo se emplean durante diez años: 15741584 , estos últimos posteriormente son sustituidos por c. $200 \mathrm{R}$ y $96 \mathrm{R}$ entre 1592-1593, y continuarán apareciendo en sus impresos hasta 1600.

Imagen 5: Muestra de tipos c. $160 \mathrm{G}, 100 \mathrm{G}$ y $99 \mathrm{C}$ utilizados por Juan Pablos, Pedro Ocharte y Pedro Balli.

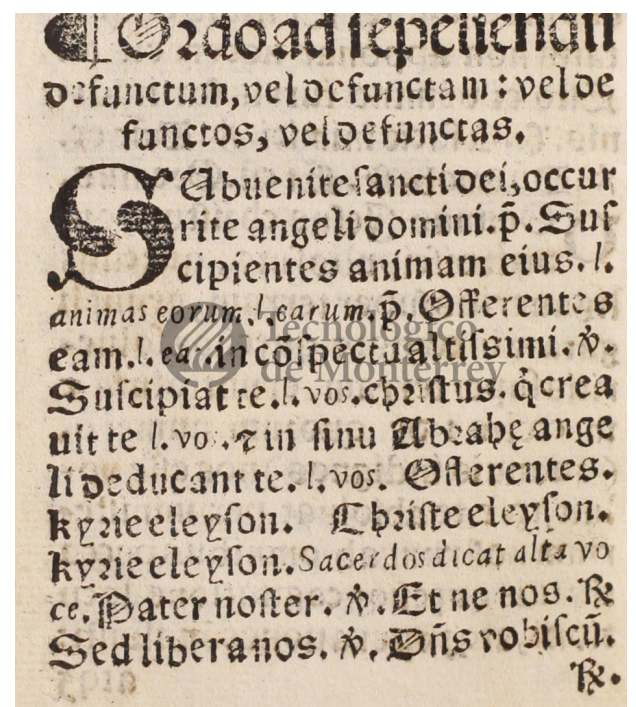

Ejemplar de [Forma brevis administrandi..., Pedro Balli, 1574-1576], hoja sin signar [8]. Col. Conway. Biblioteca de Colecciones Especiales "Miguel de Cervantes Saavedra" del Tecnológico de Monterrey, fray Miguel de Zárate, 1574-1576.

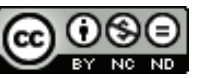

Los Derechos Reservados de la presente imagen corresponden al Tecnológico de Monterrey, ya que no tiene licencia CC 
Como sucede con Ocharte, sobre la imprenta de Balli la parcela que suscita más interés y desconcierto es la iconográfica, ya que encontramos en su producción editorial grabados que pertenecieron tanto a Juan Pablos y después, lógicamente, a su yerno, Pedro Ocharte, como a Antonio de Espinosa. Por ejemplo, de los 101 grabados que conforman el repertorio de Balli, 37 se ubican anteriormente en impresos de Juan Pablos/Pedro Ocharte y solamente 2 en Antonio de Espinosa. La situación cobra sentido al conocer el proceso inquisitorial de Ocharte, tiempo durante el cual se vio en la necesidad de dejar de ejercer el arte de la imprenta y seguramente tuvo que alquilar y/o vender sus materiales impresorios para paliar los problemas financieros derivados. En lo que respecta a los grabados xilográficos propiedad de Espinosa, los dos únicos identificados debieron pasar a manos de Balli tras el fallecimiento del primero (1576), ya que su aparición coincide cronológicamente en los impresos de Balli un poco después del deceso.

Antonio de Espinosa fue el segundo impresor mexicano; después de trabajar varios años con Juan Pablos, se independizó y montó su taller en 1559. Su producción editorial se extendió hasta su muerte, en 1576. En el terreno tipográfico Espinosa se caracterizó por tener mayor autonomía, posiblemente por haberse dedicado al oficio de fundidor de tipos, utilizando 6 tipografías de su propiedad y 1 a través de algún tipo de transacción comercial (cuyas condiciones desconocemos por no conservarse documentos al respecto). Los únicos tipos que compartió con otras imprentas fueron c. 275 G, primero, en 1561, tal vez en calidad de alquiler con los herederos de Pablos, ya que figuran en su edición de Missale romanum ordinarium, y después por medio de otra transacción comercial con Ocharte. Esta tipografía c. 275 G aparece en algunas de las ediciones de Espinosa de 1565, 1567, 1569, 1571, 1575 y 1576. La aplicación del análisis de la justificación de matrices, diseñado por Moll, ha demostrado que se trata de la misma fundición (Rodríguez, 2016, p.35-41), por lo que es lógico deducir que, al tratarse de unos tipos de cuerpo mayor, cuyo costo debió ser elevado y, además, eran utilizados para componer pocos fragmentos de cada una de las ediciones, no se justificaba tan alta inversión, y, por ello mismo, quien 
los poseía los ponía a disposición de otros talleres, sacando a su vez algún beneficio económico.

Al contrario de lo que la crítica había establecido, es interesantísimo observar que, tras la muerte de Espinosa, muchos de sus materiales pasan al taller de Ocharte y menos de ellos al de Balli. Valton sobre Balli llegó a asegurar que "su propio cuadal tipográfico provino, en parte, de la compra del material de la imprenta de Espinosa, después de la muerte de este insigne impresor" (Valton, 1939, p. 274). Sin embargo, ninguno de los tipos de Espinosa se ha identificado en las ediciones de Balli. Por otro lado, en el terreno iconográfico, de los 59 grabados recogidos en el repertorio de Espinosa, 15 figuran más tarde en las ediciones de Ocharte, a partir de 1578, y solo 2 en las ediciones de Balli a partir de 1576.

A pesar de la falta de documentación archivística, la evidencia material es contundente: se puede concluir que al fallecer el segundo impresor, Espinosa, sus herederos pusieron a la venta los materiales por partes y la mayor de ellas, sobre todo la iconográfica, la adquirió Ocharte justo en la coyuntura de la reactivación de su taller en 1578. Asimismo, se ha ubicado una fundición gótica $(99 \mathrm{G})$ del corpus de Espinosa en una edición de Ocharte de 1580: Cartilla y doctrina christiana breve y compendiosa para enseñar los niños, del fraile dominico Bartolomé Roldán. Según se mencionó antes, todo indica que Ocharte durante el proceso inquisitorial había vendido parte de sus materiales a Balli, ya que a partir de la década de los 70 figuran en sus ediciones: 4 fundiciones tipográficas (2 de tipos góticos y 2 de cursivos: c. 160 G, 100 G, 99 C y $80 \mathrm{C})$ y 37 grabados que anteriormente pertenecieron a Ocharte y no volvieron a aparecer jamás en impresos a cargo de este último. En esta tesitura es comprensible el reabastecimiento del taller de Ocharte con los materiales que los herederos de Espinosa pusieron a disposición, entre ellos, la fundición gótica 99 G y 15 grabados xilográficos.

Por último, resulta esclarecedor el uso de la ilustración en la puesta en página de cada uno de los cuatro impresores analizados. De la producción de Pablos se localizaron 41 ediciones, 28 con grabados y 13 sin ellos; de Espinosa se ubicaron 26 ediciones, 19 con grabados y 7 que no contienen; de Ocharte se localizaron 52 ediciones, 33 incluyen 
ilustraciones y 19 no; por último de los 68 impresos de Balli localizados, 44 tienen imágenes y 24 carecen de ellas. Esto significa que una mínima parte de los productos editoriales de estos impresores no presentó en su composición tipográfica algún grabado xilográfico, lo que demuestra que la relación imagen-texto fue fundamental en los impresos primitivos mexicanos. En la tabla de abajo se desglosa con mayor detalle el uso de los grabados por cada taller de impresión.

Tabla 1: Ubicación de los grabados en los impresos. Producida por la autora.

\begin{tabular}{lcccc}
\hline $\begin{array}{l}\text { Ubicación de los } \\
\text { Grabados }\end{array}$ & Juan Pablos & $\begin{array}{c}\text { Antonio de } \\
\text { Espinosa }\end{array}$ & $\begin{array}{c}\text { Pedro } \\
\text { Ocharte }\end{array}$ & Pedro Balli \\
\hline & $(1539-1560)$ & $(1559-1576)$ & $(1562-1597)$ & $(1574-1600)$ \\
\hline Portada & 6 & 3 & 11 & 31 \\
$\begin{array}{l}\text { Portada e interior } \\
\text { del texto }\end{array}$ & 18 & 14 & 16 & 10 \\
$\begin{array}{l}\text { Interior del texto } \\
\text { Total }\end{array}$ & 4 & 2 & 6 & 3 \\
\hline \hline
\end{tabular}

Tabla 2. Tipografías por imprenta y sus traspasos. ${ }^{14}$ Producida por la autora.

\begin{tabular}{l|c|c|c|c}
\hline & Juan Pablos & $\begin{array}{c}\text { Antonio de } \\
\text { Espinosa }\end{array}$ & $\begin{array}{c}\text { Pedro } \\
\text { Ocharte }\end{array}$ & Pedro Balli \\
\hline & $(1539-1560)$ & $(1559-1576)$ & $(1562-1597)$ & $(1574-1600)$ \\
\hline
\end{tabular}

Gótica

\begin{tabular}{l|l|l|l|l}
\hline c. 480 & & $1561-1576$ & & \\
\hline c. 275 & $1544-1560$ & $1561-1576$ & $1563-1589$ & \\
\hline c. 160 & $1554-1559$ & & $1563-1571$ & $1575-1584$ \\
\hline
\end{tabular}

14 El mismo color en celdas de diferentes impresores indica que se trata de los mismos tipos, es decir, que fueron traspasados de una imprenta a otra. 
Primeros vagidos de tipografía y biblioiconografía mexicana del siglo XVI

\begin{tabular}{l|c|c|c|c}
\hline & Juan Pablos & $\begin{array}{c}\text { Antonio de } \\
\text { Espinosa }\end{array}$ & $\begin{array}{c}\text { Pedro } \\
\text { Ocharte }\end{array}$ & Pedro Balli \\
\hline 136 & $1540-1550$ & & & \\
\hline c. $132 \mathrm{a}$ & $1550-1560$ & & $1565-1589$ & \\
\hline c. $132 \mathrm{~b}$ & & $1561-1576$ & 1580 & \\
\hline 99 & $1540-1550$ & & & \\
\hline $99 \mathrm{a}$ & $1550-1554$ & & $1563-1571$ & $1576-1591$ \\
\hline $99 \mathrm{~b}$ & 1556 & & & \\
\hline 100 & $1556-1559$ & & 1565 & \\
\hline 81 & $1544-1550$ & & & \\
\hline $72 \mathrm{a}$ & 1554 & & & \\
\hline $72 \mathrm{~b}$ & & & & \\
\hline
\end{tabular}

Redonda

\begin{tabular}{l|l|l|l|l}
\hline c. 240 & & & & $1574-1584$ \\
\hline c. 200 & & & $1583-1594$ & $1592-1600$ \\
\hline 132 & & & $1578-1594$ & \\
\hline 118 & $1554-1560$ & & $1566-1578$ & $1574-1600$ \\
\hline 100 & & & $1563-1571$ & \\
\hline 98 & & & $1578-1591$ & $1574-1584$ \\
\hline 96 & & $1559-1575$ & & $1593-1600$ \\
\hline 85 & & & 1597 & $1574-1600$ \\
\hline 84 & & & $1563-1594$ & \\
\hline 81 & & & $1567-1571$ & \\
\hline 70 & & & & \\
\hline
\end{tabular}

Cursiva

\begin{tabular}{l|c|c|c|c}
\hline 99 & $1554-1559$ & $1560-1575$ & $1563-1571$ & $1575-1584$ \\
\hline 80 & $1556-1559$ & 1575 & $1570-1571$ & 1574 \\
\hline \hline
\end{tabular}




\section{CONSIDERACIONES FINALES}

Como resultado del análisis material de la producción editorial de las cuatro primeras imprentas mexicanas, advertimos la importancia de la relación entre tipografías e imágenes en la puesta en página de los primeros impresos mexicanos. La combinación de tipos e ilustraciones en los primitivos impresos manufacturados en México evidencia su valor para la construcción de una nueva cultura, la cultura escrita. Nueva para los propios productores intelectuales, quienes debieron adaptar su bagaje de conocimientos a la nueva realidad, para convertir esos conocimientos en los instrumentos necesarios que ayudaran a llevar a buen puerto la empresa de evangelización e hispanización de los naturales. Nueva, novísima para los indígenas, quienes experimentaban el proceso de aculturación tipográfica con ayuda de la imagen, cuya finalidad sí les era conocida, aunque no precisamente con los mismos códigos.

Atrás de estos grandes actores operaron los magníficos artífices que lograron convertir en material impreso las obras que formaron parte del andamiaje de esa nueva cultura escrita. El reto fue enorme para todos los actores, $\mathrm{y}$, asombrosamente, muchas veces los impresores fungieron el papel de intermediarios entre unos y otros. La labor de los impresores fue admirable porque sin dominar los códigos de los unos ni de los otros, sin ser intelectuales ni naturales, contribuyeron enormemente a la conformación de la nueva cultura, y lo hicieron enfrentándose a grandes dificultades técnicas y de abastecimiento de los materiales indispensables para estampar el conocimiento en un producto impreso.

La importancia del trabajo de los primeros impresores en México muy pocas veces se ha visto desde esta perspectiva. Mucho se ha estudiado el panorama editorial mexicano bajo la lente de la trascendencia que los contenidos de las obras publicadas tuvieron en el éxito de la empresa evangelizadora; de la encomiable labor filológica, lingüística y religiosa de los autores; de la relevancia de estos textos como testimonios de un proceso histórico, político y cultural; pero en contadísimas ocasiones se ha mirado la gran relevancia del rol de esos 'pequeños empresarios', cuyo trabajo cotidiano estuvo supeditado a una gran cantidad de 
vicisitudes, tanto internas al propio taller de impresión, como externas. No es ocioso, por ello, la realización del análisis material de los impresos, mediante el cual es posible reconstruir parte de la intrahistoria de cada uno de los talleres, intrahistoria que ha permanecido oculta debido la escasez de fuentes documentales.

Recapitulando, se puede concluir que Juan Pablos llegó a México en 1539 , para instalar la primera imprenta del territorio americano continental con pocos materiales de reuso, materiales que fueron usados anteriormente por los Cromberger en Sevilla, y a su vez varios de ellos provenían de otras imprentas hispalenses, como la de Juan Varela de Salamanca o la de Stalisnao Polo. Cuando Pablos falleció los materiales de su imprenta pasaron íntegros a la de Pedro Ocharte, su yerno, en 1562, quien operó con ellos de manera ininterrumpida hasta el momento en el que fue denunciado ante la Santa Inquisición en 1572.

Antonio de Espinosa, el segundo impresor de México, trabajó de 1559 a 1576, por lo que gran parte de su producción es simultánea a la de la primera etapa de Ocharte. En este período se observa una estrecha relación entre Espinosa y Ocharte: la presencia de la tipografía c. 275 G en ediciones de ambos impresores y la aparición de la leyenda en el pie de imprenta y el colofón de Graduale dominicale secundum, de 1576, impreso por Antonio de Espinosa, a costa de Pedro Ocharte.

Durante el proceso inquisitorial de Ocharte en la década de los 70 muchos de los materiales de su imprenta pasaron a manos de Pedro Balli; podría suponerse que en un principio bajo la modalidad de alquiler, ya que muchos de ellos sí volvieron a Ocharte cuando reactivó su taller a partir de 1578; los otros, los que no volvieron, sin duda habrán sido comprados por Balli, posiblemente un poco antes de la coyuntura de la reactivación. Más o menos a la par de los 'ires y venires' de materiales entre Ocharte y Balli, falleció Antonio de Espinosa. Todo indica que sus herederos pusieron a la venta los insumos de la imprenta, de los cuales Ocharte adquirió la mayor parte y Balli casi nada. Situación comprensible, si consideramos que Balli acababa de conservar muchos de los materiales de Ocharte y este último necesitaba de nuevo más de ellos para reactivar su taller. 
La intrahistoria de los primeros impresores en México, como vemos, es bastante intrincada, y causa admiración identificar las estrategias de las que echaron mano para sortear las adversidades prácticas y técnicas, compartiendo materiales y realizando ediciones en colaboración, logrando sacar adelante el negocio editorial y ofrecer en un producto impreso las obras que los habitantes del virreinato requerían.

\section{REFERENCIAS BIBLIOGRÁFICAS}

CID, Víctor Julián. Antonio Ricardo: aportaciones a la tipografía médica mexicana del siglo XVI. Boletín Mexicano de Historia y Filosofía de la Medicina, vol. 8, n. 2, p.40-45, 2005.

DELGADO, Juan. Diccionario de impresores españoles (siglos XV-XVII). Madrid: Arco Libros, 1996.

FERNÁNDEZ, Francisco. Libros y libreros en el siglo XVI. México: Tip. Guerrero Hnos, 1914.

FERNÁNDEZ, Mercedes. Indicios y evidencias para la asignación tipobibliográfica de pliegos sueltos burgaleses del siglo XVI. In: CÁTEDRA, Pedro (Org.) La literatura popular impresa en España y en la América colonial. Formas y temas, géneros, funciones, difusión, historia y teoría. Salamanca: SEMYR-IHLL. 2006. p.437-475.

FERNÁNDEZ, Mercedes. Biblioiconografía y literatura popular impresa: la ilustración de los pliegos sueltos burgaleses (o de babuines y estampas celestinescas). eHumanista, n. 21, p.87-131, 2012a.

FERNÁNDEZ, Mercedes. De la tipobibliografía a la Biblioiconografía: consideraciones metodológicas para un Repertorio digital de materiales iconográficos de los impresos españoles del siglo XVI. In: CONDE Juan Carlos; GRIFFIN Cilve (Org.) Actas del Simposio sobre El libro en el mundo hispánico: nuevas tendencias y direcciones (Magdalen College, Oxford, 20-21 de septiembre de 2010). New York: Hispanic Seminary of Medieval Studies, 2012b. En prensa.

FERNÁNDEZ, Rosa María. Los concilios mexicanos promotores del libro y de la lectura en el siglo XVI. Investigación bibliotecológica, vol. XXII, n. 45, p.102-123, 2008. 
GARCÍA, Idalia. "Para que les den libre paso en todas partes sin que los abran ni detengan": libros para las comunidades religiosas de la Nueva España. Cuadernos de Historia Moderna, vol. 42, n. 1, p.151-173, 2017.

GARONE, Marina. Historia de la tipografía colonial para lenguas indígenas. México: CIESAS-Universidad Veracruzana, 2014a.

GARONE, Marina. Historia de la imprenta y la tipografía colonial en Puebla de los Ángeles (1642-1821). México: IIB-UNAM, $2014 \mathrm{~b}$.

GRAÑÉN, María Isabel. Los grabados en la obra de Juan Pablos. México: Apoyo al Desarrollo de Archivos y Bibliotecas de México A. C.-FCE, 2010. MAZA, Francisco de la. Enrico Martínez. Cosmógrafo e impresor de Nueva España. México: UNAM, 1991.

McLUHAN, Marshal. La galaxia de Gutenberg. Madrid: Aguilar, 1969.

MILLARES, Agustín; CALVO, Julián. Juan Pablos. Primer impresor que a esta tierra vino. México: Porrúa, 1990.

MOLL, Jaime. De la imprenta al lector. Estudios sobre el libro español de los siglos XVI al XVIII. Madrid: Arco Libros, 1994.

NORTON, Frederick John. Typographical Evidence as an Aid to de the Identification and Dating of Unsigned Spanish Books of the Sixtheenth Century. Iberomania, n. 2, p.96-103, 1970.

RODRÍGUEZ, Sergio. Un capítulo de la historia de la escritura en América: la enseñanza de las primeras letras a los indios en el siglo XVI. Anuario de estudios americanos, vol. LVI, n. 1, 1999. p.41-64.

RODRÍGUEZ, Guadalupe. Descubrimiento de dos impresos mexicanos del siglo XVI desconocidos por la tradición bibliográfica. Revista de Humanidades: Tecnológico de Monterrey, vol. 35-36, p.35-55, 2013-2014 (2016).

RODRÍGUEZ, Guadalupe. La imprenta en México en el siglo XVI. Mérida: Editora Regional de Extremadura, 2018.

STOLS, Alexandre A. M. Antonio de Espinosa, el segundo impresor mexicano. México: Universidad Nacional Autónoma de México, 1989.

STOLS, Alexandre A. M. Pedro Ocharte: el tercer impresor mexicano. México: Biblioteca Nacional, Instituto de Investigaciones Bibliográficas, Universidad Nacional Autónoma de México, 1990. 
VALTON, Emilio. Algunas particularidades tipográficas de los impresos mexicanos del siglo XVI. In: IV Centenario de la imprenta en México. Conferencias Conmemorativas. México: Asociación de Libreros de México, 1939. p.239-278.

VERVLIET, Hendrik D. L. Sixteenth-century printing types of The Low Countries. Amsterdam: Menno Hertzberger \& Co, 1968.

YMHOFF, Jesús. Las capitulares y los grabados en los impresos de Antonio de Espinosa que custodia la Biblioteca Nacional de México. Boletín de Instituto de Investigaciones Bibliográficas, n. 10, p.17-111, 1973.

YMHOFF, Jesús. Los Ocharte, Pedro Balli y Antonio Ricardo. Capitulares, grabados y viñetas utilizados en sus impresos, que conserva la Biblioteca Nacional. Boletín del Instituto de Investigaciones Bibliográficas, n. 11, p.9-98, 1974.

YMHOFF, Jesús. Iniciales ornamentales utilizadas en México, Lovaina y Amberes durante el siglo XVI. Boletín del Instituto de Investigaciones Bibliográficas, n. 18-19, p.139-142, 1981-1982.

YMHOFF, Jesús. Iniciales ornamentadas de dos abecedarios utilizadas en México y en Estella, España, durante el siglo XVI. Boletín del Instituto de Investigaciones Bibliográficas, n.1, p.17-30, 1987.

YMHOFF, Jesús. Las ilustraciones de los libros impresos en México durante el siglo XVI custodiados por la Biblioteca Nacional de México. Boletín de Instituto de Investigaciones Bibliográficas, n. 5, p.31-88, 1991.

YMHOFF, Jesús. Los impresos mexicanos del siglo XVI en la Biblioteca Nacional de México. México: UNAM, 1990. 